\title{
Information Simulation Model: Effective Risk Communication and Disaster Management in a Mixed Cultural Society
}

\author{
Virginia Clerveaux ${ }^{1}$, Toshitaka Katada ${ }^{2}$ and Kyohei Hosol ${ }^{3}$ \\ ${ }^{1}$ Doctoral Student, Department of Civil Engineering, Gunma University \\ ${ }^{2}$ Prof. Department of Civil Engineering Gunma University \\ ${ }^{3}$ Master of Engineering, Non-Profit Organization, Institute of Social Technology, Japan
}

(Received for 1 Feb., 2007 and in revised from 20 June, 2008)

\begin{abstract}
Disaster management planning requires an understanding of the issues facing a mixed cultural society to ensure effective risk information/ communication. Irrespective of the length or status of abode in the migrant destination, international standards require timely and effective communication of emergency disaster information to all. Therefore, if disaster managers are to effectively meet this challenge, models and tools must be developed to ensure efficient and equitable dissemination of information to all residents, at all phases of the disaster management cycle. We developed an information simulation model for ensuring effective dissemination of disaster information in a mixed cultural society in order to ensure effective disaster management.

The model will be an effective tool for:

(1) Communicating disaster risk and evacuation information in a mixed cultural landscape.

(2) Planning disaster risk and evacuation response.

(3) Educating decision makers on the relationship between disaster risk, information timing, and response time.
\end{abstract}

\section{INTRODUCTION}

A critical prerequisite to effective disaster management is to minimize the impact of hazards through effective communication of risk information in a timely manner and in a form that all stakeholders can comprehend. However, achieving this prerequisite is a major challenge for disaster managers, especially in an increasingly globalized world characterized by higher levels of multiculturalism as more people migrate to locations outside their culture zones where not only the language differs, but also perceptions of and attitudes towards hazard/disaster risk (Martin, 2003).

Considerable research has focused on the effects of culture on receiving and responding to warning messages. Research has found that racial and ethnic minorities are less likely to accept a warning message as credible without confirming it with other sources, such as family and social networks, often delaying reaction (Fothergill et al., 1999; Lindell and Perry, 2004). For example, after the 1989 Loma Prieta earthquake, Hispanics were more likely to have secured information from family and friends, while Anglos relied on formal English-language sources (Phillips and Ephraim, 1992). Researchers studying the 1995 F5 tornado in Birmingham found that fewer African Americans used television as their primary information source. African American and Hispanic households were less likely to evacuate for Hurricane Andrew (Gladwin and Peacock, 1997).

While this tendency to confirm and delay has been substantiated in numerous studies, it is important to recognize that differences exist among and within minority groups. For example, in one study, Mexican Americans reported using social networks to confirm information more often than African Americans (Perry and Mushkatel, 1986; see also Blanchard-Boehm, 1997). Furthermore, each population carries internal diversity: being Hispanic may mean that one's cultural framework for interpreting a warning message derives from Spain, Puerto Rico, Mexico, South America, or the Philippines. Some racial and ethnic differences in disaster response can be explained by other conditions such as poverty or geographical location in hazardous areas, but even when these factors are isolated, cultural differences appear to be an important factor related to warning messages (Lindell and Perry, 2004). Research conducted in 2000 by the International Labour Organization (ILO) (cited in Jones Rochelle) suggests that gender is an important dimension within disasters such as the Indian Ocean tsunami. It has been argued that vulnerability to natural disasters and their consequences is gendered and socially constructed, meaning that women and men face different challenges during natural disasters because their roles in society have been constructed differently. According to Morrow and Enarson (1999) (cited in Phillips and Morrow 2005), gender often works indirectly to affect disaster response. For example, the majority of single parents are female and approximately 40 percent have household incomes below the poverty line. It is therefore not surprising that many single mothers report difficulties in being able to respond effectively to hurricane warnings by preparing their homes and/or evacuating. Gender roles often place women and men in locations that influ- 
ence their vulnerability. For example, all of the women in the coastal village of Lampuuk, Indonesia were killed by the tsunami on 26 December, 2004, while children at school and men fishing at sea were spared (Times Online, 2005). Additionally, in many Islamic societies, communication is often limited to persons of the same sex i.e., men to men and women to women. This type of communication relationship often prevents women from receiving valuable disaster information that can save their lives.

Although reviews of the research literature indicate that few systematic data exists regarding minority groups in disaster (White and Haas, 1975:181-193; Cochrane, 1975:36-40), the information that is available suggests that minorities experience difficulties in adaptation that differ from those experienced by nonminorities. The probable existence of such difficulties is reflected, in some cases, by differentials in death and injury rates. Red Cross fatality counts indicate that disaster deaths are disproportionately high among ethnic minorities (Trainer and Hutton, 1972:5). The apparent discrepancy in death and injury rates between minority groups and other victims may be a function of any of these factors, or possibly of another factor; the differences may be a function of differential coping skills related to understanding emergency instructions -whether these instructions are communicated as part of a hazard warning or in a community emergency preparedness plan. Or, the differences may be due to differing willingness to undertake effective protective action once the emergency instructions are received. Minority group members, especially those whose primary language is not English, would appear to be more subject to the warningrelated difficulties just described than would nonminorities (Perry et al., 1982).

The ultimate goal of communicating forecasts, watches, and warnings is to motivate individuals to take appropriate action. However, before they do so, most persons move through a multistage decision-making process. Researchers characterize the process using a variety of terms, but in general, messages need to be heard and attended to, a process that requires comprehension and, quite frequently, confirmation. For action to occur, the recipient must believe that protective action is necessary and possible. The message must be personalized in order to motivate the desired behavioural response (Lindell and Perry, 2004; Mileti, 1999). People often wait to act while confirming the message (Mileti, 1999). Studies over the last two decades have identified population differences in the sources various groups tend to turn to for confirmation of information. However, a clear finding is that social networks are critical resources for confirming the personal relevance of a message. This appears to be especially true for women and some racial and ethnic groups (Fothergill et al., 1999; Fothergill, 1999). Getting those at risk to heed forecasts and warnings, then, requires tapping into those social networks (Heinz Center, 2002). Therefore, the challenge for disaster managers is to design effective tools/strategies that not only span language differences, but also take into consideration race and ethnicity, gender, cultural perceptions and attitudes, etc. so that the objectives of disaster risk reduction can be achieved. If we want people to heed risk communications, then "warning messages must mean something to them" (Handmer, 2002). To illustrate, there is considerable evidence that women are more likely to believe warnings, to warn others, and to want to respond. (See Major and Atwood, 2004 for a recent example.) Researchers have theorized that meaningfulness based on gender is influenced by female socialization patterns, particularly norms compelling women to obey authority and to bear responsibility for the family (Morrow and Enarson, 1999). Useful research must thus understand behavioural responses within a complex array of structural and situational variables. For example, research on racial and ethnic families, although limited, suggests that Mexican Americans may wait to take action until the entire family has been gathered, a behavioural pattern resulting from $\mathrm{cul}$ turally based values of the importance of the family. It takes longer for large families to respond, and minority families are more likely to be multigenerational. A family that has recently arrived in the U.S. may face a frustrating series of barriers between safety and critically needed information.

Language is a defining criterion of culture; differences in language can prove a formidable barrier to effective risk communication for disaster managers. Given that learning a new language requires time and patience, recent immigrants as well as visitors to a country may experience information communication gaps. In fact, some elderly people may never develop the language skills required to effectively communicate in a new society. Therefore, disaster managers need to ensure that emergency preparedness and response information is communicated in a manner that will be fully understood and accepted by different cultural groups. It is important to note that, during an emergency situation, language skills that are normally adequate may be impaired due to stress and pressure (Solis et al., 1995). Consider the classic study of the Saragosa, Texas tornado where two problems contributed to the loss of life among Spanish speakers (Aguirre et al., 1987). The first was an incorrect translation of the word "warning" from English into Spanish (Enarson et al., 2004) (cited in Phillip and Morrow, 2007). The second problem occurred because a Spanishlanguage television station did not broadcast local warnings. Language barriers have been shown to affect all aspects of the disaster management cycle, from mitigation and response to recovery. For example, Subervi-Velez et al. (1992) found that disaster agencies had too few bilingual staff for Spanish speakers and were even less prepared for Asian victims. After Hurricane Andrew, much of the early relief information was provided only in English, preventing area Latinos and Haitians from receiving needed food, medical supplies, and assistance information (Yelvington, 1997). Given the complexities of effectively communicating to mixed cultural groups, multiple mediums or channels should be used to communicate with residents during all stages of the disaster management cycle because different groups find different sources credible. For example, after the Whittier Narrows earthquake, some Latinos reported that the English-language radio tended to have better information than the Spanish-language stations; the sole Chinese newspaper was out of date and the Hispanic radio stations focused on human-interest stories, which resulted in these ethnic communities receiving incorrect information (Bolten et al., 1993).

The increase in the frequency and intensity of disasters and their associated damage in the Caribbean region is part of a worldwide trend, which results from growing vulnerability and may reflect changing climatic patterns. In the last ten years in the Caribbean and Latin America alone, natural hazards resulted in the deaths of more than 45,000 people, affected 40 million people and caused over $\$ 32$ billion in damage (IADB, 2006). At the same time, development and disaster-related policies have largely 
focused on emergency response, leaving a serious underinvestment in natural hazard prevention and mitigation (IADB, 2006). However, recently, these countries have been gradually shifting from disaster response to a more proactive approach to disaster management. While global risks seem to be increasing since 1992, the overall level of assistance available for emergencies in the world has been shrinking. These trends make it all the more necessary for the region to break the cycle of destruction and reconstruction and address the root causes of vulnerability, rather than merely treating its symptoms when disasters happen.

Although it is almost impossible to fully recoup the damage caused by a disaster, it is possible to minimize the potential risks by developing early warning strategies, preparing and implementing developmental plans to provide resilience against such disasters, mobilizing resources including communication and tele-medicinal services, and helping in rehabilitation and post-disaster reconstruction. In order to achieve these disaster loss reductions, communication of information to key sectors and vulnerable populations in multiple languages in a multicultural jurisdiction will have to play a central role in the disaster management cycle. The disaster management cycle illustrates the ongoing process by which various stakeholders in society plan for and reduce the impact of disasters, react during and immediately following a disaster, and take steps to recover after a disaster has occurred. Appropriate action at all points in the cycle leads to greater preparedness, better warnings, reduced vulnerability, or the prevention of disasters during the next iteration of the cycle. The complete disaster management cycle includes the shaping of public policies and plans that either modify the causes of disasters or mitigate their effects on people, property, and infrastructure. It is in this regard that the information simulation model was designed to assist disaster managers in planning and putting in place effective strategies to enhance disaster management.

\section{OUTLINE OF THE INFORMATION SIMULATION MODEL}

Information Transmission Simulation Model

Through various communication channels such as the mass media, loudspeakers, patrol cars, cellular phones, etc., the information simulation model disseminates warnings and other relevant information from the authorities to the public. In addition, the model depicts informal means of communication, such as telecommunication and face-to-face contact, which occur between residents (Fig. 1).

The basic structure of this simulation model is constituted according to the biased net model (Rapoport, 1979), which is a human network formation theory in mathematical sociology. The biased net model is a probability-theory-network generation model developed by imitating the information transfer structure of a nerve cell. The biased net model was applied to research for a friend selection problem by Fararo (1981), Skvoretz, (1985), etc. in social science. The basic structure of this model is similar to the original model developed by Katada et al. (2006) for use in Japan, which is considered a monocultural society. Both models take into consideration the:

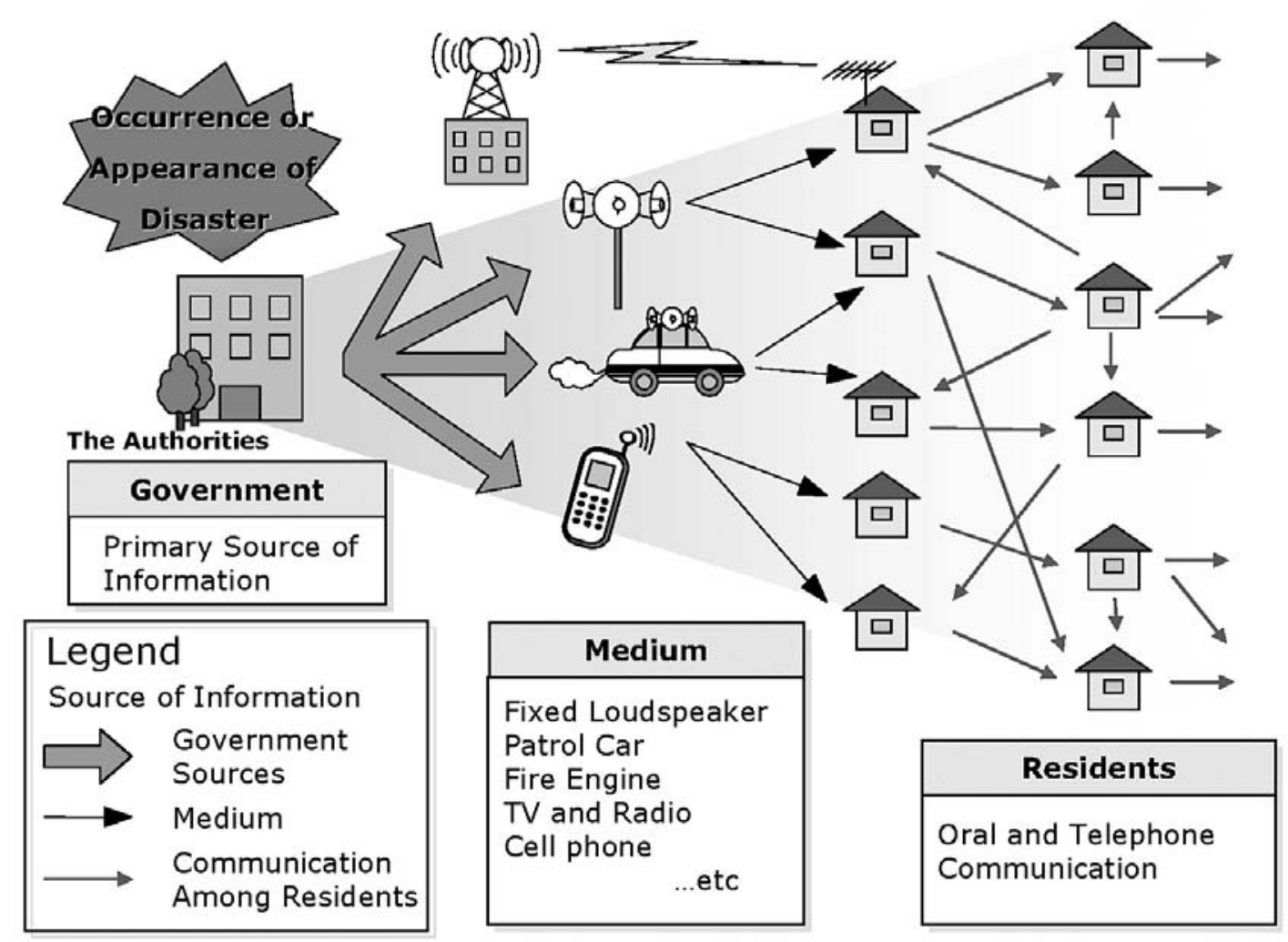

Fig. 1 Web of Communication during adisaster event 
1. Establishment of various communication mediums (patrol car, cell phone, oral communication, media, and loudspeaker).

2. Setting up of communication facilities' parameters (audible distance for loudspeakers and patrol car speakers and frequency and timing of information dissemination).

3. Siting of communication facilities and shelters.

4. Shortest and safest evacuation route (parameter: evacuation by foot).

5. Relationship between information-receive time, residents' behaviour, and impact of disaster.

The information simulation model was adapted and modified for use in a multicultural and multilanguage environment. One of the main features of this model that differentiates it from other existing models is the fact that this model recognizes that language barriers can significantly hinder appropriate responses to disaster management by impeding communication and understanding of risk information. Therefore, a new parameter of 'multiple language' for dissemination of risk information was added. The model also took advantage of the prevalence of cellular phones in society and utilized this medium to transmit information in multiple languages via SMS while also dispatching patrol cars with loudspeakers to various communities and disseminating risk information in the order of the prevalence of the languages spoken in that community. The information simulation model is based on the multicultural and multilanguage environment of the Turks and Caicos Islands (TCI).

\section{USE OF THE MODEL IN ENSURING EFFECTIVE DISASTER MANAGEMENT}

Effective disaster management helps to eliminate or reduce the probability of disaster occurrence, or its effects on societies. Ensuring that effective mitigation measures are in place so that disaster managers and residents can effectively respond to disasters is important to disaster loss reduction. In this regard, the key steps in ensuring successful disaster management strategies are: planning, communicating, and the ability to effectively respond during a disaster.

\subsection{PLANNING}

A key mitigation or preparedness measure is to imagine a worst-case scenario and then to prepare to respond to such a scenario. Planning for a disaster involves first identifying vulnerable populations, identifying the location of shelters, assessing evacuation routes, establishing communication networks to be used for dissemination of information, and educating residents on the hazard and meaning of warning messages and the various communication mediums that will be utilized.

(1) Siting of Shelters and determining evacuation routes

Using GIS as a base framework, the model identifies the best location for siting shelters. For example, the model allows the simulation of different inundation depths based on flooding that might occur from a tsunami or due to heavy rainfall. Using an $\mathrm{X}$ and $\mathrm{Y}$ coordinate system, the locations of shelters and residences can be identified and therefore, not only can the shortest evacuation route be found but multiple routes to each shelter can be identified in the event that the shortest route becomes impassable. The same principle discussed above can be used to determine the level of vulnera- bility of existing shelters and evacuation routes and to decide whether they should continue to be used.

\section{(2) Setting of Loudspeakers and Patrol Car Routes}

The model enables disaster managers to decide where to strategically position each loudspeaker so that maximum use can be made of the audible range of the speakers. The model allows one to select the best routes for dispatching patrol cars to disseminate disaster information to the public based on parameters such as areas that fall outside the audible range of the fixed loudspeakers. The maximum distance and the speed that each patrol car will be required to travel can be determined in advance by using the tsunami scenario simulator and as such, disaster managers will be able to calculate the information-receive time for each area (Fig. 2).

\section{(3) Ascertaining Evacuation Time}

Using the model, disaster managers would also be able to calculate how much time residents would require if they were to safely evacuate to the nearest shelter from their home on foot (Fig. 3). In other words, Fig. 3 is a calculation or determination of the distance from residences to shelters by foot at a constant speed. For instance, if someone is located in the red-coloured region on the map, according to the simulation, they would require over $20 \mathrm{~min}$ utes at a speed of 80 meters per minute in order to safely complete evacuation. It therefore means that for each minute that evacuation is delayed, either because of an impediment in the relay of warning information from officials or because of the time frame required for household decision making, that particular household will have less time to safely complete evacuation, and will therefore face a greater chance of being caught in the tsunami than someone who lives 5 minutes from a shelter or someone who undertook evacuation immediately following the earthquake occurrence or receipt of warning information. This type of information is relevant to both disaster decision makers and heads of households in terms of assessing the relationship between evacuation time and the number of casualties.

\section{(4) Assisting in the Evacuation Process}

Having identified the possible extent of damage due to a hazard, disaster managers can begin to plan to ensure that sufficient shelters have been located, emergency supplies have been identified and stored, and evacuation vehicles are available, etc. The model is also able to consider individual characteristics such as disability, age, sex, etc, and simulate different scenarios, thus providing disaster managers with insight into the needs of the residents that will be required to evacuate, thus ensuring effective planning.

(5) Identifying Key Stakeholders for Disaster Management

Efficient disaster management usually requires coordinated efforts with several agencies/organizations. As such, disaster managers need to identify all appropriate disaster response and recovery services. These can range from police, fire, and ambulance services to maintenance workers. Liaisons should be maintained with local emergency services so that they can respond appropriately in the event of a disaster. Obtaining multiple modes of contact from stakeholders in advance of a disaster and inputting these into the model database will allow for the easy retrieval and updating of information, in an attempt to avoid communication obstacles during a disaster.

\section{(6) Simulation Exercise}

Lastly, having decided which mediums will be used to disseminate disaster information, the language order in which disaster 


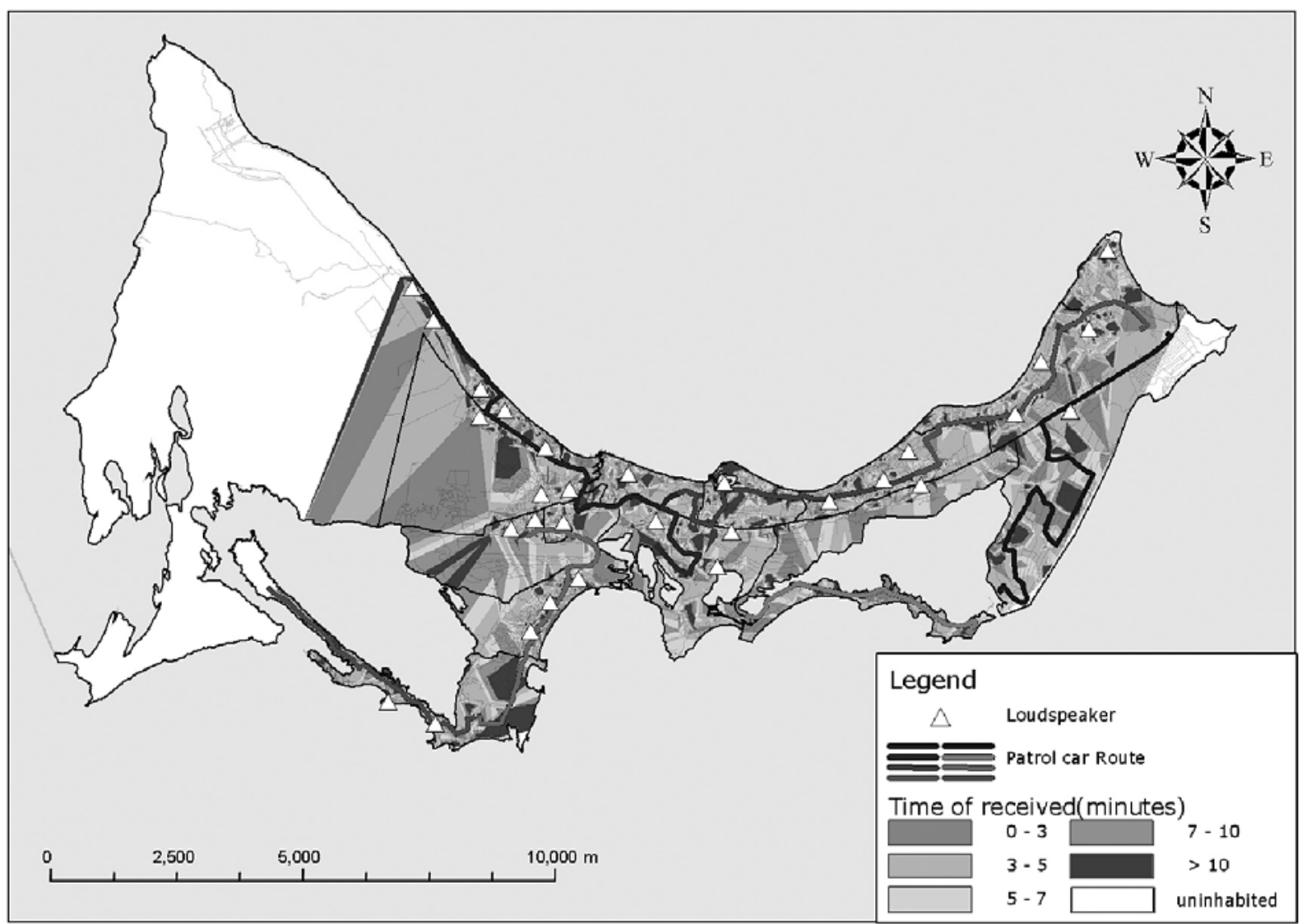

Fig. 2 Estimated Information Receive Time by District in Providenciales, Turks and Caicos Islands

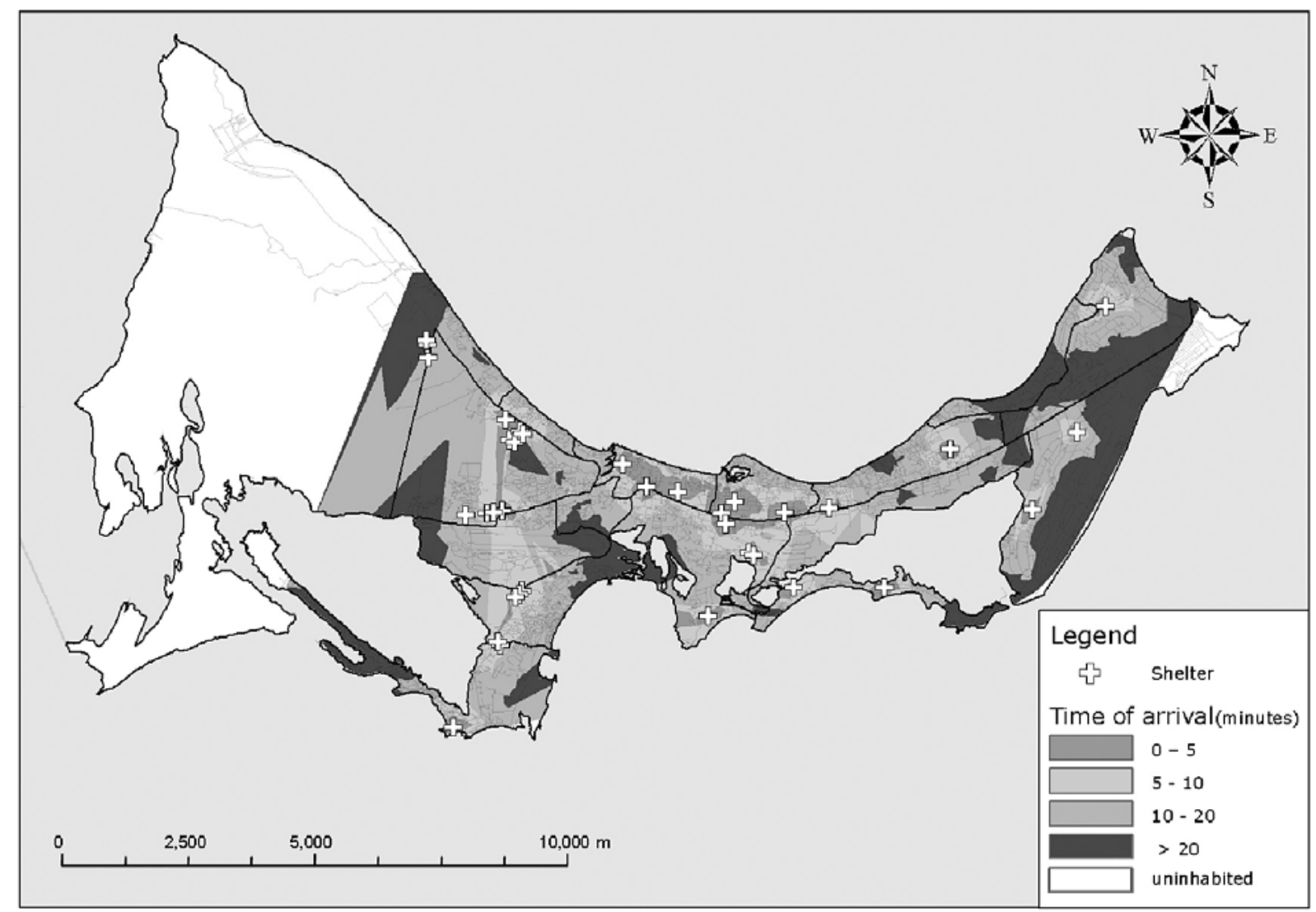

Fig. 3 Estimated Evacuation Time by District in Providenciales, Turks and Caicos Islands 
information will be disseminated depends on the area, and having put measures in place to mitigate against disasters, the next step is for disaster managers to test these plans. The only way to ensure that these plans can be effectively implemented is to test them in regular exercises on bases such as the reliability of their warning systems, emergency communications systems, and evacuation plans and providing training to emergency personnel. Exercises provide the only comprehensive way of realistically evaluating contingency plans and are therefore an important management tool for informing and motivating personnel and giving confidence to those who may be required to respond in a crisis while allowing scrutiny of their responses under controlled conditions. They should therefore reflect reality as far as is practicable. Additionally, they coordinate the activities of those who may be involved in responding to an incident allowing for teamwork and the achievement of disaster management goals.

\subsection{COMMUNICATION}

Communication is critical during an emergency and needs to be addressed thoroughly within the disaster response plan. During the onset of a disaster, from a hazard loss reduction viewpoint, transmission of disaster information in a prompt and efficient manner to residents is very important. The key to a successful communication strategy is the ability to send and receive messages using a variety of devices. The model employs a wide range of communication mediums/devices for dissemination of disaster information. These include loudspeakers, patrol car speakers, cell phones, the media, and an oral communication network. This wide range of communication mediums helps to ensure that disaster managers are mindful of the cultural context of their landscape and that the language of information disseminated is reflective of the cultural networks that are present in the society. More importantly, the model anticipates communication challenges such as power outages and therefore uses mediums such as loudspeakers and patrol cars to overcome these potential obstacles.

(1) Use of Loudspeakers

Loudspeakers can be used to transmit a unique sound (such as the sound of blowing a conch shell) for communicating disaster information. For example, three pitches can be composed and each pitch can be used to communicate three main phases of disaster information: Pitch 1: A large earthquake has just occurred at $\mathrm{X}$ location. Pitch 2: There is a possibility that the country might be affected by a tsunami; prepare to evacuate. Pitch 3: Evacuate immediately. The use of sound instead of language via the loudspeakers will ensure that there is no ambiguity or incorrect translation of the risk information being communicated to mixed cultural groups. The audible range of each speaker can be decided from the design stage in order to ensure that the maximum number of residents is covered and that the information being transmitted is clear. The model also recognizes that if loudspeakers are to be efficiently located without transmission overlap, some areas will be peripheral to the transmission range and will therefore not be covered. Therefore, patrol cars could be used to provide information to these areas.

\section{(2) Use of Patrol Cars}

As in the case of fixed loudspeakers, the audible range of patrol car speakers can be determined allowing disaster managers to determine what percentage of the population falls within the audible range of either a fixed loudspeaker or the speakers of the patrol cars. As such, disaster managers will be able to ascertain what percentage of the population will have access to disaster information. For areas that have mixed cultural groups residing together, the population size, nationality, and primary language of each household could be determined and plotted on the map. This information is important in identifying the locations of ethnic groups, since there is a tendency for persons from similar backgrounds to cluster together, and would also allow emergency managers to better customize the risk information. For each district, the primary language of each household can be tabulated and the various spoken languages can be grouped (English, French-Creole, Spanish, other). These languages can then be assigned a ranking based on prevalence, and the rank can be used to determine the order in which the patrol cars would relay the warning information. For instance, if the dominant language in a district were FrenchCreole, this language would be given priority in transmission.

(3) Use of Cellular Phones

i. Text Messages (SMS)

Use of text messages to transmit warning information to the public is an effective medium but one that is greatly underutilized during emergencies. Due to the growing use of cell phones world wide, it is believed that use of this medium to communicate will enable disaster managers to quickly transmit information in multiple languages. While it takes longer to type a message than to speak it, SMS can prove to be a reliable method of communication, even in more-severe incidents, because SMS requires less bandwidth, and SMS messages can often be sent even when there is insufficient bandwidth for voice calls.

ii. Ring Tone

An emergency ring tone with different pitches, similar to the one designed for use with the loudspeakers, can be used to alert residents of the imminent threat of a hazard. During an emergency situation, cooperation between the government and cell phone operators in the country will allow the government to transmit that sound to all cell phone holders. This sound would be heard even if the persons' cell phone were turned off or is on silent mode, increasing the distribution of information.

\section{(4) Use of the Mass Media}

The mass media can be used at all phases of the disaster management cycle as long as communication facilities have not been destroyed. Before the onset of a hazard, the mass media can be used to prepare residents for the impact of the hazard. During the occurrence of the hazard, the mass media can be used to keep residents abreast of the situation that exists outside their homes and when the threat has passed. The disaster information that is to be relayed to the residents will be issued directly from relevant government officials in the respective languages. This will help to ensure uniformity in the information that is released to the public, irrespective of the language in which it is being disseminated. If individuals are located outside the audible range of both the loudspeakers and the patrol car speakers' routes, then the media can be relied upon for transmission of risk information to those residents.

\section{(5) Use of Oral Communication}

A key feature of the information simulation model is its integration of oral communication among residents. In the context of this model, communication takes place between residents via telecommunication and face-to-face contact. This parameter was 
incorporated because in many societies and especially those that contain large mixed-culture groups, there is a tendency towards mistrust of government officials and a warning message is therefore less likely to be accepted as credible without confirming it with other sources, such as family and social networks, which often delays reaction (Fothergill et al., 1999; Lindell and Perry, 2004). This view is supported by Katada et al. (2006), who stated that there is an increase in oral communication between residents during a disaster compared to normal days and that communication parameters, such as distance of each contact, number of contacts (receivers), and timing of each contact, that usually exist on normal days, tend to decrease.

In the Caribbean, communication between neighbours, family, and friends to verify an official warning message, but more frequently for deciding what action to undertake, is commonplace and has been found to influence evacuation responses greatly (Spence et al., 2004). In addition, during a disaster, there is an increased demand by residents for updated information from officials on the status of the hazard (Katada et al., 1996). However, there is the possibility that communication systems could be damaged during a disaster and as such, oral communication networks will prove to be an effective medium.

The wide range of mediums used to communicate disaster information, both written and sound, is very important in ensuring that all social classes in society are targeted and reached in the event of a disaster. Effective communication with people of different cultures is especially challenging, since cultures provide people with ways of thinking, seeing, hearing, and interpreting the world. Thus, the same words can mean different things to different people from different cultures, even when they talk the same language. When the language is different, and translation is needed in order to communicate, the potential for misunderstanding increases (Phillips, B. et al., 2005).

\section{(6) Dissemination of Information in Multiple Languages}

Trends in disaster impact have shown that disasters, however 'natural', are profoundly discriminatory. Wherever they hit, preexisting structures and social conditions determine that some members of the community will be more affected than others. Among the differences that determine how people are affected by such disasters is that of language. The inclusion of the language parameter in the model was intended to inform disaster managers of the gap in designing a warning relay framework for dissemination in a monolanguage while operating in a multicultural and multilanguage environment.

For this paper, several scenarios were simulated using the communication mediums utilised in the model. The results for one of the scenarios using fixed loudspeakers indicated (Table 1) that when warning information is relayed, for example, in English once following an earthquake occurrence, 10.25 percent of the Englishspeaking population would receive the information. Of the population that speaks both English \& French, 8.35 percent would receive the warning. It is then assumed that this group (English/French) would then contact their friends or family who do not speak English and relay the warning to them in French, thus resulting in 0.37 percent of the French population being informed. Of the population that speaks English and 'other' language, 10.74 percent of the population would have received the information and would later relay the warning to the population segment that speaks 'other' language, thus resulting in an additional 0.81 percent of the population being informed. Since no segment of the population spoke English and Spanish or French and Spanish, that group did not receive the information.

Table 1 illustrates the dangers of transmitting warning information in one language in a multilanguage society. For example, when the language of dissemination is Spanish, only Spanish speakers received the warning information. While the data depicted in Table 1 are based on just one of the many possible scenarios that can occur, although not necessarily in the language order utilized, it nonetheless builds a strong case for the need to disseminate warning information in multiple languages when operating in a multicultural and multilanguage society.

When more than one medium was used to relay warning information (Table 2) (patrol car speakers and fixed loudspeakers) once following the occurrence of an earthquake, there was an increase of 17.6 percent in the total number of persons who would receive the warning. Additionally, both tables revealed that the more the information is relayed, the greater the percentage of the population that would receive the information. This therefore indicates that the more mediums that are utilized and the more frequent the information dissemination, the greater the chance of reaching a larger audience.

The same argument can be made for using multiple languages to disseminate warning information. The more languages used to disseminate warning information, the wider the cross section of society that the information will reach. For example, using both Table $\mathbf{1}$ and $\mathbf{2}$ above, if the warning information was disseminated in English and Spanish simultaneously, it means that persons who are bilingual and can speak English/French would be able to relay the warning to persons who speak French only. Assuming that the information was also communicated in Spanish, it therefore means that the Spanish population would have also been warned and would not be dependent on someone being bilingual, that is, speaking either English/Spanish or French/Spanish, to relay the information to them. While it is true that often in societies, there are persons that are bilingual and in some case multilingual, one cannot depend solely on this technique for dissemination of risk information. Instead, measures must be put in place to ensure that there is no discrimination in the dissemination of relevant information to populations at risk. Additionally, the presence of bilingual and multilingual persons in a society should be seen as a means of reinforcing or complementing existing multilingual communication frameworks in reaching persons that the main stream communication medium might have failed to reach. Therefore, disaster managers cannot continue to ignore the multicultural aspect of disaster management and persist in the use of a 'one size fits all' policy approach in dealing with disasters in multilanguage communities.

\subsection{RESPONSE}

People at risk from disasters, whether natural or human induced, can take actions that save lives, reduce losses and speed response, and reduce human suffering when they receive accurate warnings in a timely manner. Effective warnings should, in a timely fashion, reach every person at risk who needs and wants to be warned, regardless of the current location or activity being undertaken because effective disaster preparedness and response is important for sustainable development. However, in order to 
Table 1 Information Receive Rate by Language and Time for Loudspeakers only

\begin{tabular}{|c|c|c|c|c|c|c|c|c|}
\hline $\begin{array}{l}\text { Spread } \\
\text { Time } \\
\text { (mins) }\end{array}$ & $\begin{array}{l}\text { Language* of } \\
\text { Dissemination }\end{array}$ & $\begin{array}{l}\text { Information } \\
\text { Receiver } \\
\text { Total }(\%)\end{array}$ & English & French-Creole & $\begin{array}{l}\text { English \& } \\
\text { French-Creole }\end{array}$ & Spanish & Other & $\begin{array}{c}\text { Other } \\
\& \\
\text { English }\end{array}$ \\
\hline 1 & English & 22.2 & 10.3 & 0.4 & 8.4 & 0.0 & 0.8 & 10.7 \\
\hline 1 & French & 13.6 & 0.9 & 12.1 & 5.5 & 0.0 & 0.1 & 1.7 \\
\hline 1 & Spanish & 1.6 & 0.0 & 0.0 & 0.0 & 5.4 & 0.0 & 0.0 \\
\hline 1 & Other & 8.5 & 3.6 & 0.1 & 3.1 & 0.0 & 2.8 & 7.1 \\
\hline 1 & All & 35.0 & 10.7 & 11.7 & 8.8 & 4.7 & 3.0 & 11.3 \\
\hline 5 & English & 29.8 & 14.1 & 0.2 & 11.0 & 0.0 & 0.9 & 14.5 \\
\hline 5 & French & 19.9 & 1.7 & 16.4 & 8.8 & 0.0 & 0.4 & 3.1 \\
\hline 5 & Spanish & 3.1 & 0.0 & 0.0 & 0.0 & 10.2 & 0.0 & 0.0 \\
\hline 5 & Other & 14.0 & 5.6 & 0.1 & 5.4 & 0.0 & 5.9 & 11.8 \\
\hline 5 & All & 48.9 & 14.1 & 16.6 & 11.3 & 10.3 & 6.1 & 14.6 \\
\hline 10 & English & 30.7 & 14.6 & 0.5 & 11.4 & 0.0 & 0.6 & 14.7 \\
\hline 10 & French & 20.4 & 1.6 & 16.9 & 9.2 & 0.0 & 0.1 & 2.4 \\
\hline 10 & Spanish & 3.5 & 0.0 & 0.0 & 0.0 & 11.6 & 0.0 & 0.0 \\
\hline 10 & Other & 15.4 & 6.1 & 0.3 & 5.8 & 0.0 & 6.5 & 12.8 \\
\hline 10 & All & 50.4 & 14.5 & 17.3 & 11.2 & 11.4 & 6.7 & 14.9 \\
\hline
\end{tabular}

* 1-All-Everyone can understand the warning, they don't depend on language

Table 2 Information Received Rate every Language \& Spread Times (\%) by Loudspeaker and Patrol Car (without Mass Media, Phone)

\begin{tabular}{|c|c|c|c|c|c|c|c|c|}
\hline $\begin{array}{l}\text { Spread } \\
\text { Time } \\
\text { (mins) }\end{array}$ & $\begin{array}{l}\text { Language }{ }^{*} \text { of } \\
\text { Dissemination }\end{array}$ & $\begin{array}{c}\text { Information } \\
\text { Receiver } \\
\text { Total (\%) }\end{array}$ & English & French-Creole & $\begin{array}{l}\text { English \& } \\
\text { French-Creole }\end{array}$ & Spanish & Other & $\begin{array}{c}\text { Other } \\
\& \\
\text { English }\end{array}$ \\
\hline 1 & English & 39.8 & 18.1 & 1.1 & 18.0 & 0.0 & 1.0 & 20.4 \\
\hline 1 & French & 24.6 & 2.4 & 20.0 & 13.2 & 0.0 & 0.7 & 3.3 \\
\hline 1 & Spanish & 3.8 & 0.0 & 0.0 & 0.0 & 11.2 & 0.0 & 0.0 \\
\hline 1 & Other & 17.1 & 6.5 & 0.3 & 8.1 & 0.0 & 9.9 & 15.1 \\
\hline 1 & All & 60.9 & 17.8 & 19.7 & 17.1 & 12.0 & 10.5 & 20.4 \\
\hline 5 & English & 44.2 & 20.3 & 1.2 & 19.5 & 0.0 & 0.8 & 22.2 \\
\hline 5 & French & 28.1 & 2.7 & 22.1 & 15.4 & 0.0 & 0.9 & 4.6 \\
\hline 5 & Spanish & 4.9 & 0.0 & 0.0 & 0.0 & 15.7 & 0.0 & 0.0 \\
\hline 5 & Other & 21.4 & 8.4 & 0.4 & 9.5 & 0.0 & 11.8 & 19.0 \\
\hline 5 & All & 69.5 & 20.1 & 22.1 & 19.4 & 16.1 & 12.3 & 22.1 \\
\hline 10 & English & 44.8 & 20.5 & 1.2 & 19.8 & 0.0 & 1.3 & 22.7 \\
\hline 10 & French & 28.7 & 2.7 & 22.9 & 16.2 & 0.0 & 0.5 & 4.6 \\
\hline 10 & Spanish & 5.3 & 0.0 & 0.0 & 0.0 & 17.4 & 0.0 & 0.0 \\
\hline 10 & Other & 21.5 & 8.1 & 0.6 & 9.1 & 0.0 & 13.1 & 18.9 \\
\hline 10 & All & 70.8 & 20.6 & 22.8 & 19.6 & 17.1 & 12.5 & 22.5 \\
\hline
\end{tabular}

* 1 -All-Everyone can understand the warning, they don't depend on language 
achieve this broad distribution of information, a partnership for utilizing both government and private-owned systems will be necessary (Natural Disaster Information System Committee, 2000).

(1) Timing of Information Dissemination and Residents, Behavioural Response

After the occurrence of, for example, a large earthquake and the imminent threat of a tsunami, the prompt and efficient communication of disaster information to residents is very important to saving lives. The model allows the simulation of different scenarios based on the parameter of timing of information dissemination by the authorities and the time it takes residents to complete evacuation. The model can use the shortest evacuation route and calculate the duration of evacuation based on evacuation on foot at a speed of 80 meters per minute. Therefore, the model is able to simulate the significance of a delay in information transmission and the likely impact on loss of life. This information can be used to educate disaster managers on the importance of prompt information dissemination.

From the residents' perspective, in order to minimize casualties, effective disaster response planning must begin with an understanding of human behaviour. Rapid reporting of what is happening during a disaster can be very effective in helping people reduce damage and improve response. However, an appropriate response to a warning is most likely to occur when people have been educated about the hazard and have developed a plan of action well before the warning (Liu et al., 1996). It has been argued that the key to disaster loss reduction is the timely dissemination of warning information to those at risk. However, there are numerous instances where information was relayed in a timely manner but for various reasons, residents did not undertake evacuation. This situation was exemplified during Hurricane Katrina in the USA, 2004, Ivan in Jamaica, 2004, Hurricane Floyd in South Carolina, 1999, and the Sanriku-Earthquake, Miyagi, Japan, May 2003. Miyagi is an area known for having large earthquakes and possible tsunami threats, yet only 1.7 percent of residents evacuated due to the possibility of a tsunami occurrence. Based on this fact, if a tsunami had occurred, a high number of casualties would have been inevitable (Katada et al., 2006). There are many reasons why residents choose not to undertake or to delay evacuation as was illustrated during Hurricane Katrina in New Orleans, 2005 (see Elder, Keith et al., 2007). As part of a larger study of community evacuation warnings, Perry et al. (1981a) reported that, when warned to evacuate in the face of rising flood waters, substantially more MexicanAmericans than whites choose not to comply. In attempting to understand this response, the investigators found that, even after statistically controlling for the effects of non-English speakers and message content, Mexican-Americans tended to have less confidence in the accuracy of warning messages and believed themselves to be at less personal risk than whites (Perry and Green, 1982).

Understanding who evacuates and who does not has been one of the cornerstones of research on the pre-impact phase of both natural and technological hazards. The factors that often impede appropriate response to evacuation are, but not limited to: 'crywolf' syndrome (an evacuation order for a storm that misses), lowrisk perception, religious faith, past experience, and financial constraints, etc. It is not the aim of this model to illustrate or model the evacuation decision-making process of residents, but rather how to motivate evacuation for those that need to flee to safety, while at the same time constraining those that should stay in place. The underlying issue is that evacuation decision making and perhaps hazard decisions in general are complex processes that are not easy to categorize. However, the model acknowledges the residents' decision-making process by simulating multiple scenarios i.e., undertaking early evacuation immediately following an earthquake, delaying evacuation by 5,10 , or 15 minutes, etc. to confirm information, or simply not undertaking evacuation at all. These different scenarios were used to illustrate to residents the relationship between early evacuation and the resulting number of casualties. Additionally, scenarios were simulated to show the relationship between a delay in official warning transmission and residents' evacuation behaviour in terms of the resulting number of casualties. Based on these scenarios, it was revealed that a correlation exists between information-receive time and number of casualties and evacuation (early or delayed) and non-evacuation and number of casualties.

\section{(2) Encouraging Positive Mitigation Behaviour}

Having used the model to inform disaster managers of the most effective way of communicating warning information in a diverse society such as the TCI, and to inform the siting of shelters, positioning of fixed loudspeakers, and routes for dispatching patrol car speakers, the next component of the model from the residents' perspective is to use the model as an educational tool for encouraging positive behavioural responses to warning or other hazardrelated information.

A key strength of the information simulation model is its ability to generate two-dimensional scenario outputs of various residents' behavioural responses. Various social, psychological, and cultural factors, etc. often influence a households' decision to undertake evacuation or not. The model recognizing these barriers to effective disaster mitigation is able to educate residents through the simulation of 'life-like' scenarios about the importance of undertaking early evacuation. The realistic nature of the models' output will allow the concept of the need to heed emergency warnings to be clearly understood. In this regard, the model would be a good tool for educating residents, regardless of cultural background, about the importance of responding promptly to evacuation warnings and when appropriate, undertaking evacuation based on their own cognition of the threat, since communications from government officials can be delayed due to damage.

Studies show (Ketterer and Spada, 1993) that only if the same warning is repeated through different information channels by credible authorities, are people likely to heed it. The more detailed and specific the warning, the more credible it is and the more accepted it will be. In this regard, the model recognizes that different groups in society will find different sources credible and as such, made provision for the use of multiple mediums in the dissemination of warning information. Additionally, it has been argued that risk perception tends to increase with the frequency of warning information and also when that information originates from what is deemed a credible source. Therefore, the use of multiple mediums increases the reiteration of warnings being heard more than once and the information being relayed by what might be considered a reliable source by different groups; this results in the likelihood of increasing residents' risk perception of the need to evacuate quickly. Moreover, the inclusion of the parameter of 
oral communication between residents addresses the issue of some cultural groups finding social networks to be more reliable and trustworthy than mainstream media, which can have an advantage in not only encouraging residents to evacuate but can also provide a safety net during and after a hazard occurrence.

A barrier can also be an opportunity depending on the lens through which it is being examined. For example, it is widely stated that gender issues can present a formidable barrier to risk mitigation. But it may also be argued that gender may positively influence the warning response. Since women by nature or through their socialization process are considered to be caretakers, the model can be used to educate females or female-headed households of the need to evacuate early to reduce casualties in their family; since a 10-minute delay in evacuation can cause serious injury and even death, such a scenario would no doubt appeal to women. As such, women represent a potential key target for public outreach and education. Conversely, if men tend toward riskier behaviours, the model can simulate various scenarios to depict what is likely to occur if evacuation is taken late, especially when elderly and young children are involved in evacuating on foot, when roads are inundated and some are impassable, and when attempting to evacuate late at night. The model as such might appeal to men who generally see themselves as the protectors of the family.

The model addresses the complexities that often result due to language differences or incorrect translation of warning information from one language to another by the use of a siren-type pitch to issue warnings. The use of this method means that, regardless of the primary language, persons would still be able to understand the warning. Secondly, the model does not rely on the media to translate the warning into various languages; instead, the model makes recommendations for the warning information to be directly issued in the three official languages spoken in the country by the disaster office.

\section{CONCLUSION}

Vulnerability to natural hazards may be reduced through hazard education and effective warnings, which is the basic premise on which the information model was constructed. In this regard, the tsunami model can be considered a type of dynamic digital "hazard map" as it informs, educates, and identifies vulnerable populations. As the results of various scenarios can be depicted in two-dimensional or graphical formats, the presentation of the results is more realistic and thus more likely to appeal to residents, irrespective of cultural and language differences, about the need to ensure that they have taken sufficient measures to protect themselves, their family, and property from various disasters. Given the wide range of devices/mediums used to communicate risk information, this tool will be effective in communicating risk information to a mixed cultural group and in encouraging prompt evacuation from vulnerable areas in the face of an imminent threat. For disaster managers, the tsunami model is a type of digital disaster manual for assessing the effectiveness of current disaster management strategies that are in place.

\section{BIBLIOGRAPHY}

Aguirre, Ben et al. Sarasota, Texas, tornado May 22, 1987. Washington
DC: National Academy Press.

Blanchard-Boehm, Denise (1997). "Risk Communication in Southern California: ethnic and gender response to the 1995 revised, upgraded earthquake probabilities.” Quick Response Report, Natural Hazards Research and Applications Information Center.

Bolton, P.A., E.B. Liebow, and J.L. Olson (1993). Community Context and Uncertainty Following a Damaging Earthquake: Low-Income Latinos in Los Angeles, California. The Environmental Professional 15: 24047.

Cochrane, Harold (1975). Natural Disasters and Their Distributive Effects. Boulder, Colo.: Institute for Behavioural Sciences, University of Colorado.

Effective Disaster Warnings: Report by the Working Group on Natural Disaster Information Systems, Subcommittee on Natural Disaster Reduction. National Science and Technology Council Committee on Environment and Natural Resources (NSTCCEN). November 2000.

Elder, Keith, Sudha Xirasagar, Nancy Miller, Shelly Ann Bowen, Saundra Glover, and Crystal Piper (2007). African Americans' Decisions Not to Evacuate New Orleans before Hurricane Katrina: A Qualitative Study. April 2007, Vol. 97, No. Supplement_1. American Journal of Public Health S124-S129@ 2007 American Public Health Association, DOI: 10.2105/AJPH.2006.100867.

Enarson, Elaine (2000). Gender and Natural Disasters. ILO Infocus Programme on Crisis Response and Reconstruction. http://www.awid.org/go.php?list=analysis\&prefix $=$ analysis\&item $=00$ 226 (retrieved 17 July, 2007).

Enarson, Elaine (2004). Social Vulnerability Course, FEMA Higher Education Project. http://training.fema.gov/emiweb/edu/completeCourses.asp

Fararo, T.J. (1981). Biased networks and social structure theorems. Social Networks, 2, 1-18.

Fothergill, Alice, Enrique G.M. Maestas, and JoAnne DeRouen Darlington (1999). "Race, Ethnicity, and disasters in the United States: a review of the literature." Disasters 23/2:156-173.

Fothergill, Alice (1999). “Woman's roles in a disaster." Applied Behavioural Science Review7 (2):125-143.

Fothergill, Alice (1996). "Gender, Risk and Disaster." International Journal of Mass Emergencies and Disasters 14/1: 33-56.

Gender and Disaster Network. http://online.northumbria.ac.uk/ geography_research/gdn/ Includes a list of researchers and an extensive bibliography on gender and disasters.

Gladwin, Hugh and Walter Gillis Peacock (1997). "Warning and Evacuation: A Night for Hard Houses.” Pp. 52-74 in Peacock, W.G., Morrow, B.H. and Gladwin, H. Hurricane Andrew: Ethnicity, Gender and the Sociology of Disasters. Miami, FL: International Hurricane Research Center, Florida International University.

Handmer, John (2002). "Are Flood Warnings Futile? Risk communication in emergencies." Australasian Journal of Disaster and Trauma Studies http://www.massey.ac.nz/ trauma/issues/2000-2/handmer.htm (accessed 10 January, 2005).

Heinz Center (2002). Human links to coastal disasters. Washington, D.C.: The H. John Heinz Center for Science, Economics and the Environment.

Inter-American Development Bank (IADB) (2006). Disaster Risk Management, http://www.iadb.org/sds/ENV/site_2493_e.htm (retrieved December 2006).

Jones, Rochelle (2000), Gender and Natural Disasters: Points to Ponder, http://www.disasterwatch.net/women_tsunami\%20links/Gender\%20a 
nd\%20natural\%20disasters.htm (retrieved 14 March, 2007).

Katada, T., Aoshima, S., and Oikawa. Y. (1996). Oral Communication Network Model for Refuge Warning against Disaster. Proceedings of Japan Urban Planning Society, 31, 757-762 (in Japanese).

Katada, Toshitaka and Noriyuki Kuwasawa (2006). Development of Tsunami Comprehensive Scenario Simulator for Risk Management and Disaster Education, Journal of infrastructure planning and management, Vol. 62, No. 23, pp. 250-261 (in Japanese).

Ketterer and Spada, 1993. Der Mensch als Betroffener und Verursacher von Naturkatastrophen: Der Beitrag umweltpsy-chologischer Forschung. Pp. 73-107 in Naturkatastropehn und Katastrophenvorbeugung (Natural Disasters and Disaster Prevention) (in German), edited by Erich Plate, Lars Clausen, Ulrich de Haar, Hans-B. Kleeberg, Gunter Klein, Georg Matthe B, Rainer Rothm and Hans U. Schmincke. Weinheim, Germany: Deutsche Forschungsgemeinschaft.

Lindell, Michael K., and Ronald W. Perry (2004). Communicating Environmental Risk in Multiethnic Communities. Newbury Park, CA: Sage.

Liu, S., L. E. Quenemoen, J. Malilay, et al. (1996). Assessment of a SevereWeather Warning System and Disaster Preparedness, Calhoun County, Alabama, 1994. American Journal of Public Health, Vol. 86, p. 87-89.

Major, Ann Marie and L. Erwin Atwood (2004). “Assessing the usefulness of the U.S. Department of Homeland Security's Terrorism Advisory System.” International Journal of Mass Emergencies and Disasters 22/2: 77-102.

Martin, F. LaTanya (2003). Cultural Differences in Risk Perception: An Examination of USA and Ghanaian Perception of Risk Communication. MSc. Thesis. Virginia Polytechnic Institute and State University.

Mileti, Dennis (1999). Disasters by Design. Washington D.C.: Joseph Henry Press.

Perry, Ron and Alvin Mushkatel (1986). Minority Citizens in Disasters. Athens, GA: University of Georgia Press.

Perry W. Ronal, Marjorie R. Green (1982). The Role of Ethnicity in the Emergency Decision-Making Process. Sociological Inquiry, Vol. 52, No. 4, Fall. The University of Texas Press.

Perry, Ronald, Michael Lindell, and Marjorie Green (1981a). Crisis Communication: Ethnic Differentials in Interpreting and Acting on Disaster Warnings. Social Behaviour and Personality 10 (1): 97-104.
Society for Personality Research (Inc).

Phillips, Brenda D. and Betty Hearn Morrow (2007). Social Science Research Needs: A focus on Vulnerable Populations, Forecasting and Warnings. Natural Hazards Rev., Volume 8, Issue 3, pp. 61-68 (August 2007)

Phillips, Brenda and Mindy Ephraim (1992). "Living in the Aftermath: blaming processes in the Loma Prieta earthquake." Working Paper No. 80, Natural Hazards Research and Applications Information Center.

Rapoport, A. (1979). A probabilistic approach to networks. Social Networks, 2, 1-18.

Skvoretz, J. (1985). Random and biased networks: simulations and approximation. Social Networks, 7. 225-261.

Solis, Y. Gabriela et al. (1995). Guideline on Cultural Diversity and Disaster Management. Final Report Produced within the Canadian Framework for the International Decade for Natural Disaster Reduction. www.epc-pcc.gc.ac/pub/manuals/en_cult.htm (retrieved 12 October, 2005).

Spence, B. et al. (2004). Behaviour of Residents of Flood Prone Areas in Relation to Emergency Situation. Report Submitted to: The Caribbean Disaster Emergency Response Agency.

Sue, D.W. \& Sue, D. (1990). Counseling the culturally different. Toronto: Wiley.

Subervi-Velez, F.A., M. Denney, A. Ozuna, and C. Quintero (1992) Communicating with California's Spanish-speaking Populations: Assessing the Role of the Spanish-Language Broadcast Media and Selected Agencies in Providing Emergency Services. Report, California Policy Seminar, Berkeley.

Times Online. 2005. “The town left without women.” Accessed 1/12/2005 at http://www.timesonline.co.uk

Trainer, P. and J. Hutton (1972). An Approach to the Differential Distribution of Deaths and Disaster. Paper presented at the meeting of the Midwest Council on Social Research in Aging, Kansas City.

White, Gilbert and Gene Haas (1975). Assessment of Research on Natural Hazards. Cambridge, Mass.: MIT Press.

Yelvington, K.A. (1997). Coping in a Temporary Way: The Tent Cities. In W.G. Peacock, B.H. Morrow and H. Gladwin (eds.) Hurricane Andrew: Ethnicity, Gender, and the Sociology of Disasters. Routledge, New York. 